\title{
Comparison of Microleakage of Class V Restoration with Self-etch and Selective-etch Adhesive Systems: An In Vitro Study
}

\author{
Alperen M Yalniz ${ }^{1}$, Ahmet O Karacan ${ }^{2}$, Cagatay Cakar ${ }^{3}$, Yildirim H Bagis ${ }^{4}$
}

\begin{abstract}
Purpose: This in vitro study is to evaluate the microleakage of the universal and self-etch adhesives in selective-etch and self-etch techniques by evaluating dye penetration.

Materials and methods: In this study, a total of 48 restoration and caries-free maxillar or mandibular anterior teeth were used. Standardized class $V$ cavities (1.5 mm deep, not beveled, rounded corners) were prepared on buccal surfaces of all teeth, which were gingival edges above from the enamel-cement junction. A total of 48 teeth were randomly separated into four groups. The first group was restored with Clearfil S3 Bond Plus (Kuraray, Tokyo, Japan) in the self-etch technique. The second group was restored with single bond universal (SBU) adhesive L-pop (3M ESPE, St. Paul, USA) in the self-etch technique. The third group was restored with Clearfil S3 Bond Plus (Kuraray, Tokyo, Japan) in the selective-etch technique. The fourth group was restored with single bond universal adhesive L-pop (3M ESPE, St. Paul, USA) in the selective-etch technique. Final finishing and polishing of the restorations were performed by using discs (ZenitFlex, Munich, Germany). They were thermocycled for 5,000 thermal cycles between water baths at $5^{\circ} \mathrm{C}$ and $55^{\circ} \mathrm{C}$. All surfaces were isolated with two layers of nail polish, except up to $1 \mathrm{~mm}$ from the restoration margin for correct evaluation of the microleakage. The apices of all teeth were covered with a composite resin (Clearfil Majesty Esthetic, Kuraray, Tokyo, Japan). The teeth were stored in an oven with $2 \%$ methylene blue solution for 24 hours. The samples were embedded in acrylic resin in plastic molds.

Results: Microleakage scores (count and percentages) for all four groups are shown in Table 2. The Kruskal-Wallis test was applied to determine the differences between microleakage scores in the four study groups at a 0.05 level of significance. No statistically significant difference was found $(p>0.05)$.

Conclusion: The two adhesive systems showed clinically acceptable microleakage values in two different application techniques.

Keywords: Adhesive, Composite resin, Microleakage, Self-etch adhesives.

International Journal of Prosthodontics and Restorative Dentistry (2019): 10.5005/jp-journals-10019-1229
\end{abstract}

\section{INTRODUCTION}

Adhesion is defined as where two different surfaces are held together by physical or chemical bonding. In restorative dentistry, adhesion comes about between mineralized tooth structures and restorative materials. ${ }^{1,2}$ Adhesive systems play an important role in the adaptation of resin-based materials to tooth structures. Therefore, manufacturers are trying to find the ideal adhesive system and adhesive technique for a better adaptation. ${ }^{3}$ Dental adhesive systems have changed from the past to present, and producers have focused on developing single-stage and easy-touse systems. These developments provide ease of application and save treatment time on the patient to dentists. Dental adhesive systems can be divided into two main groups as "total-etch" and "self-etch." 4,5

Total-etch systems are the oldest systems on the market and can be applied in two or three stages. In three-stage systems, first phosphoric acid is applied to enamel and dentin. The etching procedure is aimed to increase the surface area and surface energy of the enamel. ${ }^{6}$ Then, the tooth is washed and dried with an air-water spray and primer applied. The primers replace water in the collagen network to ease the infiltration of the monomer. ${ }^{5}$ Then, the adhesive resin is applied to primer applied tooth. In twostage systems, primer and adhesive resin are in the same bottle and applied after the etching process. ${ }^{5,7}$ Total-etch systems are still the gold standard in terms of dental adhesion, but today's trend is on the development of self-etch systems. ${ }^{4,5,8,9}$

\footnotetext{
${ }^{1-4}$ Department of Restorative Dentistry, Faculty of Dentistry, Ankara University, Ankara, Turkey

Corresponding Author: Alperen M Yalniz, Department of Restorative Dentistry, Faculty of Dentistry, Ankara University, Ankara, Turkey, Phone: +90 531661 5061, e-mail: alp.yalniz@gmail.com
}

How to cite this article: Yalniz AM, Karacan AO, et al. Comparison of Microleakage of Class V Restoration with Self-etch and Selective-etch Adhesive Systems: An In Vitro Study. Int J Prosthodont Restor Dent 2019;9(2):51-55.

Source of support: Nil

Conflict of interest: None

From the view that the smear layer protects the dentine and pulp against irritations, it is intended to obtain a hybrid layer containing the smear layer. ${ }^{10}$ Unlike total-etch systems, hydrophobic and hydrophilic monomers, polymerization initiators, solvents, stabilizers, and filler particles are blended in self-etch systems. ${ }^{11}$ Self-etch systems can be applied in one or two stages. ${ }^{4,7}$ In twostage self-etch systems, acid and primer have been combined in a bottle. This is called the self-etch primer. The adhesive resin is applied after the self-etch primer has been applied. In singlestage self-etch systems, acid, primer, and adhesive resin have been combined in one bottle. Thus, the application is simplified by reducing the number of steps. ${ }^{8,12}$ All components in one bottle are called "all-in-one" systems (Figs 1 and 2). 


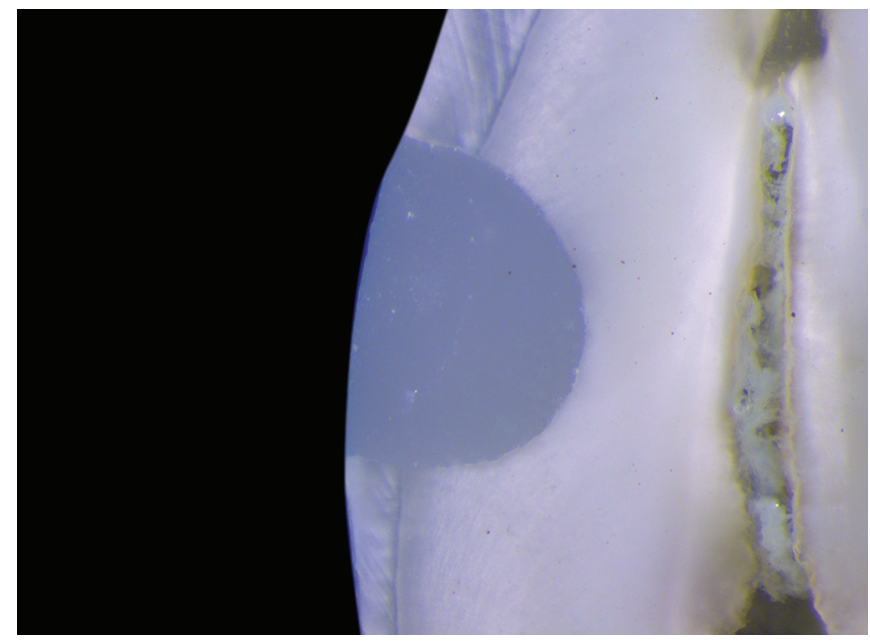

Fig. 1: Sample of experimental second group which is restored with single bond universal adhesive L-pop (3M ESPE, St.Paul, USA) in self-etch application technique (x12.5)

Self-etch systems contain special acidic monomers. These monomers contain acidic carboxylate and phosphate groups and thus act as "conditioners." These monomers provide enamel and dentin etching. ${ }^{11,13}$ Due to these features of self-etch systems, they are easy to use and enable facile application. ${ }^{4,14}$

While both of these systems provide an adequate connection to the dentine, total-etch systems have been preferred on the enamel. ${ }^{4,15,16}$ To strengthen the bonding of self-etch adhesives to enamel, acid application only to the enamel edges is called "selective-etch." The purpose of selective-etch is to increase enamel bonding force like total-etch. ${ }^{17}$ Nowadays, the purpose of dental adhesive systems is to get the same result in different dental tissues (caries, sclerotic dentin, enamel, and dentin). ${ }^{4}$

Universal adhesives that can be used in multimodes have been marketed as the latest-generation adhesive systems. Universal adhesives can be used in combination with "self-etch" and "totaletch" adhesive systems, as well as in the enamel "selective-etch," as a "self-etch" adhesive system in dentin. ${ }^{18,19}$ Universal adhesives have content similar to single-stage self-etch adhesives. They have been designed according to the "all-in-one" concept. ${ }^{19}$ Universal adhesives, which allow users to use different application techniques, are most suitable for cavity. ${ }^{20}$

Composite restorative materials are frequently used today. However, there are some disadvantages such as microleakage, color changes, and polymerization shrinkage. ${ }^{21,22}$ Polymerization shrinkage is one of the most important reasons of microleakage. Although adhesive systems have been developing, microleakage didn't have totally prevented. Microleakage allows the ingress of bacteria, ions, and fluids. Microleakage may cause postoperative sensitivity, recurrent caries, marginal discoloration, and pulp inflammation. ${ }^{23-25}$

Numerous studies about microleakage have still been made from the past to the present. The aim of this in vitro study was to evaluate the microleakage of class $\mathrm{V}$ composite restorations by using two different adhesive systems with two different application techniques.

\section{Materials and Methods}

The present study has compared the microleakage between Clearfil S3 Bond Plus (Kuraray, Tokyo, Japan) and Single Bond Universal

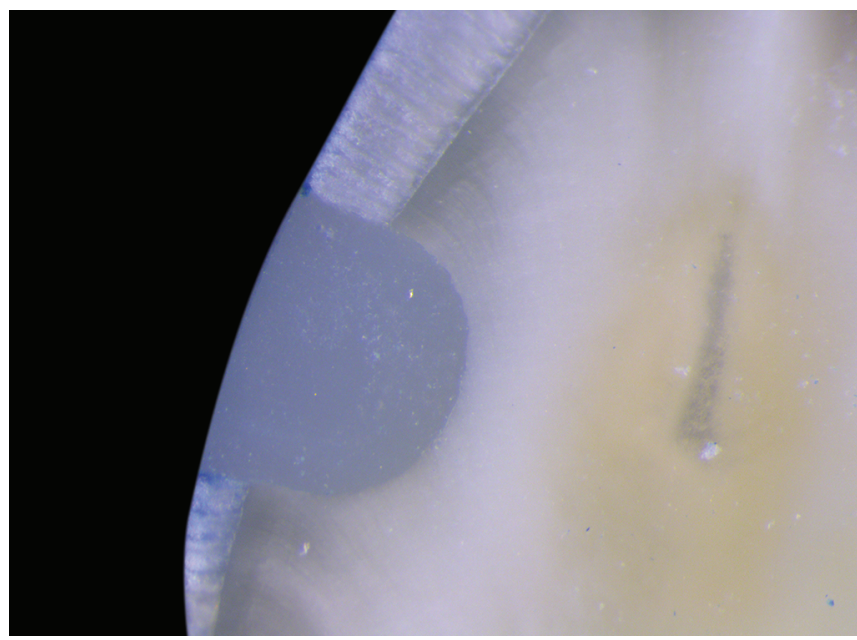

Fig. 2: Sample of experimental fourth group which is restored with single bond universal adhesive L-pop (3M ESPE, St.Paul, USA) in selective-etch application technique $(\mathrm{x} 12.5)$

Adhesive L-pop (3M ESPE, St. Paul, USA) in selective-etch and selfetch application techniques.

The research protocol used was approved by the Ethics Committee of the relevant institution of Ankara University. In this study, a total of 48 restoration and caries-free maxillar or mandibular anterior teeth were used. Before starting study, teeth were cleaned out of soft tissue residues under water with the help of a wire brush. Standardized class V cavities ( $1.5 \mathrm{~mm}$ deep, not beveled, rounded corners) were prepared on buccal surfaces of all teeth, which were gingival edges above from the enamel-cement junction. A total of 48 teeth were randomly separated into four groups.

The first group was restored with Clearfil S3 Bond Plus (Kuraray, Tokyo, Japan) in the self-etch technique. The second group was restored with single bond universal adhesive L-pop (3M ESPE, St. Paul, USA) in the self-etch technique. The third group was restored with Clearfil S3 Bond Plus (Kuraray, Tokyo, Japan) in the selectiveetch technique. The fourth group was restored with single bond universal adhesive L-pop (3M ESPE, St. Paul, USA) in the selectiveetch technique.

In the self-etch application technique, Clearfil S3 Bond Plus (Kuraray, Tokyo, Japan) was applied into the cavity for 10 seconds and the entire cavity wall was dried sufficiently by blowing mild air for more than 5 seconds until the bond didn't not move. Then, it was light-cured for 10 seconds with a LED dental curing light device (Acteon, France). Single bond universal adhesive L-pop (3M ESPE, St. Paul, USA) was applied into the cavity for 10 seconds and the entire cavity wall was dried sufficiently by blowing mild air for more than 5 seconds until the bond didn't not move. Then, it was light-cured for 10 seconds with a LED dental curing light device (Acteon, France).

In the selective-etch application technique, enamel margins were etched by $37 \%$ phosphoric acid (i-Gel, i-Dental, Lithuania) for 20 seconds. Then, they were rinsed and dried by an air-water spray. All cavities were completed with a nanohybrid composite resin (Clearfil Majesty Esthetic, Kuraray, Tokyo, Japan) according to manufacturers' instructions.

The restoration surfaces were finished, respectively, with coarse code zp.01, medium code zp.02, fine code zp.03, and super fine code zp.04 discs (Zenit Flex, Munich, Germany) using an air-driven watercooled rotary tool. All the teeth were stored in an oven for 24 hours at $37^{\circ} \mathrm{C}$. They were thermocycled for 5,000 thermal cycles between 
Table 1: Microleakage scores (count and percentages) of the groups

\begin{tabular}{|c|c|c|c|c|c|c|c|c|}
\hline \multirow[b]{3}{*}{ Scores } & \multicolumn{8}{|c|}{ Groups } \\
\hline & \multicolumn{2}{|c|}{$\begin{array}{l}\text { Clearfil S3 bond plus } \\
\text { self etch }\end{array}$} & \multicolumn{2}{|c|}{$\begin{array}{l}3 M \text { single bond universal } \\
\text { adhesive L-pop self etch }\end{array}$} & \multicolumn{2}{|c|}{$\begin{array}{l}\text { Clearfil } 53 \text { bond plus } \\
\text { selective etch }\end{array}$} & \multicolumn{2}{|c|}{$\begin{array}{l}3 M \text { single bond universal } \\
\text { adhesive L-pop selective etch }\end{array}$} \\
\hline & Count & Column N\% & Count & Column N\% & Count & Column N\% & Count & Column N\% \\
\hline Scores 0 & 8 & 66.7 & 8 & 66.7 & 9 & 75.0 & 10 & 88.3 \\
\hline Scores 1 & 3 & 25.0 & 4 & 33.3 & 2 & 16.7 & 1 & 8.3 \\
\hline Scores 2 & 0 & 0.0 & 0 & 0.0 & 1 & 8.3 & 0 & 0.0 \\
\hline Scores 3 & 1 & 8.3 & 0 & 0.0 & 0 & 0.0 & 0 & 8.3 \\
\hline
\end{tabular}

Table 2: Kruskal-Wallis and Chi-square test statistics $(p=0.05)$

\begin{tabular}{ll}
\hline Test statistics & Score \\
\hline Chi-square & 0.850 \\
df & 3 \\
Asymp. sig. & 0.838 \\
\hline
\end{tabular}

water baths at $5^{\circ} \mathrm{C}$ and $55^{\circ} \mathrm{C}$. All surfaces were isolated with two layers of nail polish, except up to $1 \mathrm{~mm}$ from the restoration margin for correct evaluation of the microleakage. The apices of all teeth were covered with the composite resin (Clearfil Majesty Esthetic, Kuraray, Tokyo, Japan). The teeth were stored in an oven with $2 \%$ methylene blue solution for 24 hours. The samples were embedded in acrylic resin in plastic molds. For the examination of microleakage, the teeth were perpendicular sectioned in buccolingual direction and evaluated under a 12.5× stereomicroscope (Figs 1 and 2).

It was scored as follows: -0 no dye penetration, -1 dye penetration less than half of the cervical/occlusal wall, -2 dye penetration more than half of the cervical/occlusal wall, -3 dye penetration along the axial wall.

The statistical analysis of microleakage measurements was performed using the SPSS 11.5 program (SPSS, Chicago, Illinois, USA). The Kruskal-Wallis variance analysis was used to compare the microleakage amounts of self-etch and selective-etch methods of the materials used $(p=0.05)$. Descriptive statistics were reported in the form of counts and percentages.

\section{Results}

Microleakage scores (count and percentages) for all four groups are shown in Table 1. Table 2 shows that the Kruskal-Wallis test was applied to determine the differences between microleakage scores in the four study groups at a 0.05 level of significance. No statistically significant difference was found $(p>0.05)$. Also, Table 2 shows that the Chi-square test, $(p=0.850)$, showed no statistical difference among the microleakage scores of the different adhesive system techniques.

\section{Discussion}

This in vitro study compares different adhesive system modes (selfetch and selective-etch) in point of microleakage in class $V$ cavities of upper or lower permanent anterior extracted human teeth.

Adhesion is the most affected property in using adhesive systems. The adhesion is only proportional to microleakage. The literature has shown that three main factors can affect the adhesion. The first factor is the composite polymerization shrinkage that leads to stresses at the adhesive interface. The second factor is that the substrate is a biological tissue that makes adhesion difficult. The third factor is the chemical composition of the adhesive. ${ }^{33}$

Polymerization shrinkage in composite resin restorations is induced to microleakage. ${ }^{34}$ In restorative dentistry, many materials and different techniques are developed to reduce polymerization shrinkage. ${ }^{35,36}$ Some of them are effective in reducing polymerization shrinkage but cannot completely eliminate it. ${ }^{35}$ It is suggested that the light sources used in the polymerization of composite resins affect the clinical success of the restorations. ${ }^{37,38}$ Therefore, various light sources, such as halogen light source (QTH), LED, plasma arc (PAC), and laser, have been developed. LED light sources have some advantages: no heat during polymerization, short polymerization time, light, wireless, and ergonomy. ${ }^{39}$ Because of these advantages, an LED light device was used in this study. However, it is reported that there is no significant difference between the LED and halogen light source in the different light sources leakage surveys by Oberholzer et al. ${ }^{40}$ It has been reported that in order to keep minimum the polymerization shrinkage resulting from the polymerization of composite resins, the composite layers applied to the cavity should not exceed $2 \mathrm{~mm}$, and that the light source should be positioned at the closest possible point to the polymerized surface. ${ }^{41,42}$

Microleakage is an important indicator of the clinical durability of a restorative material. Because microleakage between the tooth and the filling material is a problem in adhesive restorations, in these restorations, dyes, radioisotopes, bacteria, air pressure, and scanning electron microscopy are used for the evaluation of microleakage. ${ }^{43}$ It is the easiest and most common method to examine the sections taken under the stereomicroscope after the sections are stored in the dye solution. ${ }^{44,45}$ For this reason, in this study, microleakage has been investigated in vitro by the dye penetration method that is an easy, cheap, quantitative, and comparable technique. By the way, the evaluation of microleakage has been done using a stereomicroscope at $12.5 \times$ magnification, which is enough to evaluate dye penetration.

For self-etch adhesives, the acidic properties of the active monomers are responsible for dissolving the smear layer and demineralizing the underlying dentin. This demineralization is selflimiting because the acidity of the monomers is gradually buffered by the mineral content of the dentin. This implies that the resulting morphological aspect of the bound interface depends largely on the properties of the dentin to which the adhesive is applied and on the aggressiveness of the acidic monomers. ${ }^{46}$ Adhesives with a pH above 2.5 are defined as "ultra-mild self-etch adhesives." These "ultra-mild self-etch adhesives" interact with both enamel and dentin tissue superficially. Adhesives with a pH above 2 are defined as "mild self-etch adhesives." These "mild self-etch adhesives" reach the hybrid layer. ${ }^{4}$

Siso et al. in their in vitro study have compared the microleakage of SBU in self-etch, selective-etch, and total-etch. As a result of this study, the minimum microleakage value for SBU has been reported in the total-etch mode. ${ }^{47}$ Souza-Junior et al. have demonstrated that selective-etching provides better marginal integrity for Clearfil Tri-S, which proves to be an efficient additional step for class I 
composite restorations. However, this study has no evidence of reducing microleakage. ${ }^{48}$ Gupta et al. in their in vitro study have evaluated microleakage with total-etch, self-etch, and universal adhesive systems in class $V$ restorations.

It has been suggested that one of the reasons of failure in studies with composite resins is that the in vitro studies do not exactly simulate the oral conditions. ${ }^{26}$ To simulate oral conditions in in vitro studies, aging methods such as water degradation, thermocycling, and occlusal loading (chewing stimulator) are used. ${ }^{27}$ To create similar clinical conditions, we have chosen the thermocycling, which is the commonly used aging method. The effect of thermocycling has been the subject of discussion among researchers. ${ }^{28,29}$ Despite the fact that it is the most common used method of aging restoration for microleakage evaluation, there is no consensus in the literature. ${ }^{30}$ The number of cycles used in microleakage studies varies in literature. Crim et al. and Gale et al. have stated that the number and duration of the cycle don't affect microleakage. ${ }^{31,32}$ All the teeth were thermocycled for 5,000 cycles to look alike aging of the restoration in the mouth and then were stored in $2 \%$ methylene blue solution to detect microleakage.

As a result of this study, all adhesives under investigation have shown microleakage. ${ }^{46}$ In the study by Motevaselian et al., microleakage scores have been similar in the use of three different adhesive systems. ${ }^{49}$

With today's developments in dentistry, adhesive systems are available with many new dental restorative materials. With this progress, we believe that the new generation of adhesive systems and resin-based composite applications can eliminate the failures such as microleakage, which is one of the most important reasons for the dental restorations. According to the results acquired in the present study, no statistically significant difference has been found between the groups-neither between the selectiveetch and self-etch techniques nor between the universal and self-etch adhesives. The two adhesive systems showed clinically acceptable microleakage values in two different application techniques.

\section{References}

1. Duke ES. Adhesion and its application with restorative materials. Dent Clin North Am 1993;37(3):329-340.

2. Latta MA, Barkmeier WW. Dental adhesives in-contemporary restorative dentistry. Dent Clin North Am 1998;42(4):567-577.

3. Frankenberger R, Perdigao J, et al. "No-bottle" vs "multi-bottle" dentin adhesives a microtensile bond strength and morphological study. Dent Mater 2002;17(5):373-380. DOI: 10.1016/S0109-5641(00)00084-1.

4. Van MeerbeekB, Yoshihara K, et al. State of the art of self-etch adhesives. Dent Mater 2011;27(1):17-28. DOI: 10.1016/j.dental.2010.10.023.

5. Pashley DH, Tay FR, et al. State of the art etch-and-rinse adhesives. Dent Mater 2011;27(1):1-16. DOI: 10.1016/j.dental.2010.10.016.

6. Muñoz MA, Luque l, et al. Immediate bonding properties of universal adhesives to dentine. J Dent 2013;41(5):404-411. DOI: 10.1016/ j.jdent.2013.03.001.

7. Reis A, Zander-Grande C, et al. Effect of mode of application on the microtensile bond strength of a self-etch and etch-and-rinse adhesive system. Oper Dent 2010;35(4):428-435. DOI: 10.2341/09-319-L.

8. Breschi L, Mazzoni A, et al. Dental adhesion review: aging and stability of the bonded interface. Dent Mater 2008;24(1):90-101. DOI: 10.1016/ j.dental.2007.02.009.

9. Van Meerbeek B, De Munck J, et al. Buonocore memorial lecture adhesion to enamel and dentin: current status and future challenges. Oper Dent 2003;28(3):215-235.
10. Hamouda IM, Samra NR, et al. Microtensile bond strength of etch and rinse vs self-etch adhesive systems. J Mech Behav Biomed Mater 2011;4(3):461-466. DOI: 10.1016/j.jmbbm.2010.12.007.

11. Van Landuyt KL, Snauwaert J, et al. Systematic review of the chemical composition of contemporary dental adhesives. Biomaterials 2007;28(6):3757-3785. DOI: 10.1016/j.biomaterials.2007.04.044.

12. Marchesi G, Frassetto A, et al. Adhesive performance of a multi-mode adhesive system: 1-year in vitro study. J Dent 2014;42(5):603-612. DOI: 10.1016/j.jdent.2013.12.008.

13. Moszner N, Salz U, et al. Chemical aspects of self-etching enameldentin adhesives: a systematic review. Dent Mater 2005;21(10): 895-910. DOI: 10.1016/j.dental.2005.05.001.

14. Perdigão J, Munoz M, et al. Immediate adhesive properties to dentin and enamel of a universal adhesive associated with a hydrophobic resin coat. Oper Dent 2014;39(5):489-499. DOI: 10.2341/13-203-LR.

15. Erickson RL, Barkmeier WW, et al. Bond strength of self-etch adhesives to pre-etched enamel.Dent Mater 2009;25(10):1187-1194.DOI: 10.1016/ j.dental.2009.04.004.

16. Rotta M, Bresciani P, et al. Effects of phosphoric acid pretreatment and substitution of bonding resin on bonding effectiveness of selfetching systems to enamel. J Adhes Dent 2007;9(6):537-545.

17. Buonocore MG. A simple method of increasing the adhesion of acrylic filling materials to enamel surfaces. J Dent Res 1955;34(6):849-853. DOI: 10.1177/00220345550340060801.

18. de Goes MF, Shinohara MS, et al. Performance of a new one-step multimode adhesive on etched vs non-etched enamel on bond strength and interfacial morphology. J Adhes Dent 2014;16(3):243-250.

19. Wagner $A$, Wendler $M$, et al. Bonding performance of universal adhesives in different etching modes. J Dent 2014;42(7):800-807. DOI: 10.1016/j.jdent.2014.04.012.

20. Hanabusa M, Mine A, et al. Bonding effectiveness of a new "multimode" adhesive to enamel and dentine. J Dent 2012;40(6):475-484. DOI: 10.1016/j.jdent.2012.02.012.

21. Köhler B, Rasmusson CG, et al. A five-year clinical evaluation of class II composite resin restorations. J Dent 2000;28(2):111-116. DOI: 10.1016/ S0300-5712(99)00059-7.

22. Collins CJ, Bryant RW, et al. A clinical evaluation of posterior composite resin restorations: 8-year findings. J Dent 1998;26(4):311-317. DOI: 10.1016/S0300-5712(97)00019-5.

23. Agrawal VS, Parekh VV, et al. Comparative evaluation of microleakage of silorane-based composite and nanohybrid composite with or without polyethylene fiber inserts in class II restorations: An in vitro study. Oper Dent 2012;37(5):E1-E7. DOI: 10.2341/11-353-L.

24. Pioch T, Staehle HJ, et al. Effect of dentin adhesives on the enameldentin/composite interfacial microleakage. Am J Dent 2001;14: 252-258.

25. Kaya S, YigitÖzer S, et al. Comparison of apical microleakage of dual-curing resin cements with fluid-filtration and dye extraction techniques. Med Sci Monit 2015;21:937-944. DOI: 10.12659/ MSM.892741.

26. Huang GT, Söderholm KJ. In vitro investigation of shear bond strength of a phosphate based dentinal bonding agent. Scand J Dent Res 1989;97(1):84-92. DOI: 10.1111/j.1600-0722.1989.tb01434.x.

27. Gu XH, Kern M. Marginal discrepancies and leakage of all-ceramic crowns: influence of luting agents and aging conditions. Int J Prosthodont 2003;16(2):109-116.

28. Doerr CL, Hilton TJ, et al. Effect of thermocycling on the microleakage of conventional and resin-modified glass ionomers. Am J Dent 1996;9(1):19-21.

29. Yap AU. Effects of storage, thermal and load cycling on a new reinforced glass-ionomer cement. J Oral Rehabil 1998;25(1):40-44. DOI: 10.1046/j.1365-2842.1998.00192.x.

30. Raskin A, D'Hoore W, et al. Reliability of in vitro microleakage tests: A literature review. J Adhes Dent 2001;3(4):295-308.

31. Crim GA, Shay JS. Microleakage pattern of a resin-veneered Cavity liner. J Prosthet Dent 1987;58(3):273-276. DOI: 10.1016/00223913(87)90038-2. 
32. Gale MS, Darvell BW. Thermal cycling procedures for laboratory testing of dental restorations. J Dent 1999;27(2):89-99. DOI: 10.1016/ S0300-5712(98)00037-2.

33. Guéders AM, Charpentier JF, et al. Microleakage after thermocycling of 4 etches and rinse and 3 self-etch adhesives with and without a Flowable composite lining. Oper Dent 2006;31(4):450-455. DOI: 10.2341/05-55.

34. Baygin O, Korkmaz FM, et al. Effects of different types of adhesive systems on the microleakage of compomer restorations in Class $\mathrm{V}$ cavities prepared by Er,Cr:YSGG laser in primary teeth. Dent Mater J 2012;31(2):206-214. DOI: 10.4012/dmj.2011-133.

35. Ikemi T, Nemoto K. Effects of lining materials on the composite resin's shrinkage stresses. Dent Mater 1994;13(1):1-8. DOI: 10.4012/ dmj.13.1.

36. Tolidis K, Nobecourt A, et al. Effect of a resin-modified glass ionomer liner on volumetric polymerization shrinkage of various composites. Dent Mater 1998;14(6):417-423. DOI: 10.1016/S0300-5712(99)00016-0.

37. Albers HF. Tooth-colored restoratives: Principles and techniques. 9th ed., London: BC Becker; 2002. pp. 111-125.

38. Hilton TJ, Broome JC. Direct posterior esthetic restorations. Fundamentals of Operative Dentistry, 3rd ed., Illinois: Quintessence Publishing Co.; 2006. pp. 289-339.

39. Stahl F, Ashworth SH, et al. Light emitting diode (LED) polymerization of dental composites: flexural properties and polymerization potential. Biomaterials 2000;16:41-47.

40. Oberholzer TG, DuPreez IC, et al. Effect of LED curing on microleakage, shear bond strength and surface hardness of a resin-based composite restorations. Biomaterials 2005;26(18):3981-3986. DOI: 10.1016/ j.biomaterials.2004.10.003.

41. Charbeneau GT. Principles and Practice of Operative Dentistry. Philadelphia: Lea \& Febinger; 1988. pp. 163-165.

42. Lacy AM, Young DA. Modern concepts and material for the pediatric dentistry. Pediatr Dent 1996;18:469-475.

43. Öztürk AN, Usumez A, et al. Influence of different light source on microleakage of class $\mathrm{V}$ composite resin restoration. J Oral Rehabil 2004;31(5):500-504. DOI: 10.1111/j.1365-2842.2004.01273.x.

44. Hanks GT, Wataha JC, et al. Permeability of biological and synthetic molecules through dentine. J Oral Rehabil 1994;21(4):475-487. DOI: 10.1111/j.1365-2842.1994.tb01162.x.

45. Ferrari M, Garcia-Godoy F. Sealing ability of new generation adhesive restorative materials placed on vital teeth. Am J Dent 2002;15:(2)117-128.

46. Gupta A, Tavane P, et al. Evaluation of Microleakage with Total-etch, Self-etch and Universal Adhesive Systems in Class V Restorations: An In vitro Study. J Clin Diagn Res 2017;11(4):ZC53-ZC56.

47. Siso SH, Bayrak I, et al. Bond Strengths and Microleakage of Composites Bonded with Novel Adhesives. 5th International Congress on Adhesive Dentistry; 2013.

48. Souza-Junior EJ, Prieto LT, et al. Selective enamel etching: effect on marginal adaptation of self-etch LED-cured bond systems in aged Class I composite restorations. Oper Dent 2012;37(2):195-204. DOI: 10.2341/11-184L.

49. Motevaselian F, Yassine E, et al. In vitro Microleakage of Class V Composite Restorations in Use of Three Adhesive Systems. J Islam Dent Assoc Iran Winter 2016;28(1):14-19. 